\title{
AS FONTES DE INFORMAÇÕES INFLUENTES NO PROCESSO DE TOMADA DE DECISÃO DOS AGRICULTORES DO ASSENTAMENTO CONQUISTA DA LIBERDADE
}

\author{
LEADING INFORMATION SOURCES TO THE FARMERS \\ DECISION MAKING PROCESS OF THE "FREEDOM'S \\ CONQUEST" (CONQUISTA DA LIBERDADE) SETTELMENT
}

\author{
Ísis Mota Krüger \\ Universidade Federal de Pelotas - Pelotas - RS - Brasil \\ Mário Conill Gomes \\ Universidade Federal de Pelotas/Campus Capão do Leão - Capão do Leão - RS - Brasil
}

\begin{abstract}
Resumo: A tomada de decisão e a racionalidade no âmbito da agricultura familiar estão intimamente ligadas em muitos estudos que visam ao desenvolvimento dos pequenos agricultores, que apresentam importância social e econômica para o país. O objetivo deste trabalho foi avaliar o efeito das fontes de informações sobre a tomada de decisão dos agricultores do assentamento Conquista da Liberdade, localizado no Município de Piratini, no Estado do Rio Grande do Sul. O trabalho foi baseado em questionários e para a tabulação dos resultados foi utilizada uma planilha de cálculo. O leite é o principal produto comercializado pela maioria das famílias, e o motivo da escolha do principal produto é a renda estável, seguido da limitação da área. A Empresa de Assistência Técnica e Extensão Rural - EMATER é apontada como importante extensionista para as decisões dos agricultores. Os programas de TV, as palestras e cursos na área e a experiência aparecem como principais influentes na tomada de decisão. Analisando os reais influentes na tomada de decisão dos agricultores, pode-se facilitar a comunicação e o acesso à informação.
\end{abstract}

Palavras-chave: Desenvolvimento. Administração Rural. Reforma Agrária. Racionalidade; Comunicação.

Abstract: Decision making and rationality in the scope of family agriculture are closely linked in many studies about small farmers' development, which have social and economic importance to Brazil. This study aimed to evaluate the effect of information sources on the farmers' decision making process from "Conquista da Liberdade" (Freedom's Conquest) settlement, in Piratini county, Rio Grande do Sul State, Brazil. The work was based on questionnaires and spreadsheet software was used to analyze data. Milk is the main product sold by most families which generates a fixed income in a context of area limitation. EMATER is considered an important extension agent to farmers' decisions. TV programs, lectures and courses in the area as well as experience accounts in most part to the decision making. Analyzing information sources in the decision making of farmers can facilitate the access to them and the communication process.

Keywords: Development. Farm Management. Agrarian Reform. Rationality. Communication.

\section{INTRODUÇÃO}

A importância da agricultura familiar para o país é notável tanto no âmbito econômico quanto social. Econômico no que tange à questão de produção para consumo da população brasileira, por manter $79 \%$ dos postos de trabalho agrícola e também por representar a maioria em números de estabelecimentos rurais no país. Social por suprir a necessidade de consumo de suas famílias e ainda pela 
conservação ambiental e do território (KUNZLER, WIZNIEWSKY, 2012; IBGE, 2009).

Tanto é assim que a agricultura familiar tem sido uma das principais beneficiárias das políticas de desenvolvimento propostas pelo Ministério do Desenvolvimento Agrário, como no caso do Programa de Desenvolvimento Sustentável do Programa Territórios da Cidadania - PRONAT (ORTEGA, 2015).

No entanto, espera-se que os melhores resultados de uma política pública aconteçam quando $o$ público e as atividades aos quais se destinam não permaneçam estagnados, ou seja, evoluam. Isso significa que o desenvolvimento em bases sustentáveis não depende somente do respeito às questões sociais, culturais, ambientais, mas também às técnicas e econômicas. Assim, uma transformação permanente dependeria do sucesso das iniciativas postas em prática por meio de projetos de melhoria dos distintos públicos-alvo ligados aos programas e políticas.

Os assentamentos de reforma agrária, que são basicamente compostos por produtores familiares, também têm sido segmentos normalmente prioritários dentro de diversas políticas públicas de desenvolvimento. Esses agricultores apresentam uma racionalidade peculiar e complexa, consequência do ambiente físico, social, cultural, institucional, político e econômico em que estão inseridos (XAVIER, 2010; LIMA et al. 2005).

Para Lima et al.(2005), o processo de tomada de decisão desses agricultores é contingente dessa racionalidade e pode tornar-se ainda mais complexo caso enfrentem um problema não rotineiro ou estratégico. Nesses casos, a informação, desempenha papel fundamental, pois é baseado nela que a família configura seu sistema agropecuário a médio e longo prazo (LIMA et al., 2005). Nessas condições, as decisões tomadas pelos produtores são baseadas em variados objetivos, e muitos deles não apresentam origem econômica. Por fim, outro fator a ser destacado na tomada de decisão dos agricultores é a incerteza inerente ao cenário agrícola que compreende a falta de acesso às informações do agricultor (SEPULCRI, 2006).

A complexidade pode aumentar ainda mais ao considerar-se a forma de organização coletiva dos assentamentos de reforma agrária. Nesses casos, a obtenção de informações, o julgamento e a produção de decisões sobre como se vai dispor da terra, dos bens e, principalmente, do trabalho tem um caráter também coletivo.

A racionalidade e a tomada de decisão no contexto da agricultura familiar em assentamentos de reforma agrária compõe o cenário ao qual este trabalho está dirigido. Mais especificamente, enfoca-se o papel da informação no processo de tomada de decisão.

Tendo em vista esse cenário, selecionou-se o assentamento Conquista da Liberdade que está localizado no Município de Piratini, Rio Grande do Sul. Esta escolha foi conveniente porque parte do assentamento optou por uma experiência de organização coletiva de produção, enquanto que outra parte optou por uma organização em lotes individuais. Neste assentamento foi criada a cooperativa Cooperativa de Produção Agropecuária Vista Alegre - COOPAVA, que essencialmente abrange os assentados que optaram pela estratégia coletiva de organização. 
Neste trabalho, procura-se caracterizar o perfil dos produtores e compreender as principais fontes de informação e sua importância no processo decisório dos agricultores do assentamento Conquista da Liberdade.

\section{MARCO TEÓRICO}

\subsection{Agricultura familiar: racionalidade, informação e tomada de decisão}

Não se tem a intenção, e nem seria possível neste espaço, de propor uma discussão aprofundada sobre o conceito de agricultura familiar. No entanto, faz-se necessário tecer alguns comentários sobre essa importante categoria analítica, bem como, sua racionalidade e o papel da informação no processo de tomada de decisão.

A origem da agricultura familiar no Brasil é diversificada e regionalmente contingente. É esta diversidade na origem que responde pela multiplicidade de "agriculturas familiares" do Brasil (WANDERLEY, 2014). Por outro lado, não se pode deixar de destacar que a criação da lei 11.326/2006 representou um passo muito importante para a definição de agricultura familiar, especialmente no que se refere à operacionalização de políticas públicas.

No entanto, apesar de estabelecer uma definição e um marco legal necessário, a lei é insuficiente para abranger os distintos fenômenos estudados, principalmente no campo da gestão da unidade produtiva (BAIARDI e ALENCAR, 2014). É necessário entendê-la na sua essência e, para isso, ao invés de um conceito, talvez seja melhor alinhar-se com alguns princípios fundamentais: a) a propriedade dos meios de produção e o trabalho administrativo realizado por pessoas com laços de parentesco; b) a maior parte do trabalho executivo é realizada pela família; c) existe uma linha de sucessão familiar (GUANZIROLI e CARDIM, 2000).

A partir desses princípios, muitos autores podem servir de chave interpretativa para explicar a racionalidade do agricultor familiar (GASSON, 1973; CHAYANOV, 1974; WEBER, 1978; ABRAMOVAY, 1992; SIMON, 1997). No entanto, dentro do escopo do artigo, parece mais lógico entender seu comportamento pela lente da racionalidade limitada de Herbert Simon. Além do que, a importância da informação e a estrutura do processo decisório de Simon também estão na base dos diferentes desdobramentos teóricos sobre a tomada de decisão (veja DEWEY, 1953; KEPNER e TREGOE, 1976; MINTZBERTG et al. 1976).

Embora a informação desempenhe um papel importante no contexto do processo decisório e da tomada de decisão, ela deve ser vista como meio e não como um fim (MINTZBERG, 1975; BIO, 1988). A correta obtenção e uso de informações na fase de planejamento se reflete posteriormente em um processo decisório mais fluido e uma tomada de decisão mais segura (FREITAS et al., 1997).

Smeltzer et al.(1988) classificam as fontes de informação entre Pessoais (formais ou informais) e Impessoais (escrita e oral). Errington(1986) as classifica segundo a sua origem, podendo ser externa ou interna; segundo os meios de comunicação, em observação direta, verbal ou escrita e segundo as próprias fontes, podendo ser dados numéricos, comentários de pessoas e a própria experiência do decisor ao longo do tempo. 
Para Solano et al.(2003), as fontes de informação preferidas pelos agricultores são aquelas advindas das suas relações pessoais e as mais utilizadas por eles são as informações oriundas de pessoas confiáveis, como os membros da família e os extensionistas. Em todos esses trabalhos, a ideia de confiança parece emergir como um elemento comum aos agricultores no momento de selecionar as fontes de informação, planejar e decidir.

\subsection{Desenvolvimento territorial, assentamentos rurais e cooperativismo}

O desenvolvimento tem sido de especial interesse para o âmbito agrário, especialmente durante as duas últimas décadas (ORTEGA, 2015). A reforma agrária, que passou de uma visão revolucionária das décadas de 1950 e 1960 a uma perspectiva alinhada ao atual paradigma territorial, vem representando o esforço nacional de incorporar a atividade agrícola na proposta de desenvolvimento do país (LEITE e ÁVILA, 2007). O importante a destacar-se é que, no início da década de 2000, observa-se um ponto de inflexão conceitual (do setorial ao territorial) com o qual se passa a entender a formulação das políticas de desenvolvimento destinadas ao rural (NAVARRO, 2001).

Aliás, é digno de nota sublinhar que a agricultura familiar transformou-se em um segmento prioritário para o desenvolvimento. Também merece destaque o fato do Plano Nacional de Reforma Agrária - II PNRA vincular a reforma agrária ao novo paradigma de desenvolvimento territorial (BRASIL, 2004). Há, inclusive, a priorização de territórios com assentamentos na operacionalização de alguns programas como, por exemplo, o "Territórios da Cidadania" e o de "Aquisição de Alimentos" (ORTEGA, 2015).

A compra de terras ociosas e improdutivas pelo Estado e a distribuição para agricultores em assentamentos vem sendo o principal instrumento para operacionalizar a política de reforma agrária no Brasil (BRASIL, 2004). A organização dos agricultores assentados tem sido preferencialmente em lotes individuais. Outra forma de organização foi por meio das Cooperativas de Produção Agropecuária - CPA, que representavam o ideal de coletivização socialista do Movimento dos Trabalhadores Rurais Sem Terra - MST. No início da década de 1990, a maior parte das CPAs criadas entrou em crise como reflexo da falta de sintonia entre os ideais de organização coletiva do MST e a cultura tradicional dos trabalhadores rurais, familiar e individual (SCOPINHO, 2006; MARTINS, 2004). Ainda restam exemplos dessas experiências e a COOPAVA é um deles.

\section{METODOLOGIA}

\subsection{Objeto de estudo: características do assentamento Conquista da Liberdade}

O assentamento estudado neste trabalho é o Conquista da Liberdade, estabelecido em 11 de fevereiro de 1992 no Município de Piratini, no Estado do Rio Grande do Sul. A localidade, que se encontra às margens da BR-293, era antigamente ocupada pela empresa agroindustrial denominada CICA Alimentos S/A em uma área de 1232 ha. O local foi entregue com algumas estruturas já estabelecidas, como galpões, casa, refeitórios, estrebarias e até pomares de pêssego. 
Em agosto de 1995, foram assentadas 50 famílias e, com o intuito de organizar e oficializar o trabalho coletivo, 31 delas criaram a COOPAVA. Nessa cooperativa, os assentados decidiram que não haveria lotes individuais, morariam em uma agrovila e os meios de produção seriam adquiridos e utilizados em comum. Todos contribuiriam com seu trabalho e a comercialização dos produtos seria por intermédio da cooperativa, bem como a divisão dos resultados. Hoje, a cooperativa possui uma usina de beneficiamento (pasteurização) do leite tipo $C_{\text {, }}$ que é comercializado na cidade de Piratini e também nas cidades vizinhas Candiota e Pinheiro Machado. Além do leite, a COOPAVA comercializa produtos agroecológicos, como sucos, geleias de frutas, melado, hortaliças, dentre outros produtos, todos com a marca "Terra Livre". O produto mais comercializado pela cooperativa é o leite.

Já nos lotes individuais, os agricultores que assim optaram decidiram por uma maior autonomia nas decisões de investimento, produção e apropriação dos frutos do trabalho. O produto mais comercializado pelos produtores individuais é o leite. Há outros produtos, mas somente para o autoconsumo das famílias. Os lotes individuais são de aproximadamente 20 ha e foi considerado na partilha que ao menos 13 ha fossem produtivos. É importante mencionar que as famílias que se encontram em lotes individuais também se organizaram em uma associação, onde trocam conhecimentos e informações para conduzir a produção com reuniões periódicas. Essa associação possui uma sede onde são ministrados cursos por intermédio de instituições como a EMATER e também são feitas parcerias para a produção, de sementes e outras culturas que eles comercializam.

Atualmente, o assentamento possui 44 famílias das quais 11 ainda permanecem com a COOPAVA e as outras 33 estão em lotes individuais. A COOPAVA é reputada por técnicos de órgãos de extensão como referência no que tange à produção agroecológica, com exceção do leite. Também a maioria dos demais agricultores dos lotes individuais adota diversas práticas agroecológicas, e o assentamento é citado por técnicos da região como um dos mais organizados e desenvolvidos.

\subsection{Instrumento de análise}

Neste estudo de caso, optou-se por uma abordagem descritiva de pesquisa. O instrumento utilizado foi o questionário e, para melhor coletar os dados, foram realizados três questionários distintos: um, específico para os agricultores dos lotes individuais, outro, para os cooperados da COOPAVA e o último, que contemplou questões para ambos.

O questionário aplicado para todos os assentados foi constituído por 28 questões; o questionário com questões diferenciadas para os produtores individuais continha 10 questões; e, para os cooperados da COOPAVA, continha 8 questões.

O primeiro encontro para o estudo foi realizado com o intuito de apresentar os objetivos do trabalho para dois representantes do assentamento: um, representando os lotes individuais e outro, representando a cooperativa. Nesse primeiro momento, também foram recolhidos dados referentes às características e histórico do assentamento. Após o primeiro encontro, os questionários foram 
aplicados em três dias, no segundo semestre de 2013, por família, para que se pudesse atingir o maior número de assentados.

Para a elaboração deste artigo, não foram utilizadas todas as questões. Utilizaram-se as questões referentes às fontes de informações que os produtores têm acesso, quais influenciam na tomada de decisão e em qual ordem. Também foram utilizadas algumas questões referentes à assistência técnica que esses produtores usufruem; como eles a avaliam para o andamento da produção; quais assistências que identificam como principais e quais gostariam de receber.

O questionário também abrangeu algumas questões do perfil do agricultor e familiares para uma caracterização mínima como: idade, escolaridade, participação e visão do trabalho na cooperativa, tempo de serviço na agricultura e de seus ascendentes e quanto essa experiência é considerada na tomada de decisão.

As respostas às questões foram tabuladas em planilha de cálculo, organizados em gráficos e tabelas de tal modo a facilitar a interpretação dos resultados.

\section{RESULTADOS E DISCUSSÃO}

\subsection{Questões aplicadas especificamente para os cooperados da COOPAVA}

Foram entrevistadas 9 famílias das 11 cooperadas. Duas delas não foram entrevistadas, ou por não terem sido encontradas, ou por não terem se disposto a responder. Todos são descendentes de agricultores, sempre trabalharam com agricultura e estão na cooperativa e no assentamento desde sua fundação.

Durante a aplicação do questionário, enfrentou-se um problema delicado, inesperado e de difícil abordagem: a desistência por parte de alguns agricultores cooperados do projeto coletivo e a consequente migração para lotes individuais. A desistência gerou acúmulo de trabalho para os membros restantes ao ponto de apontarem que a distribuição do trabalho deveria melhorar. Por ser um tema sensível e imerso em conflitos, percebeu-se que os agricultores evitavam discuti-lo com pessoas externas à cooperativa. As outras duas famílias responderam que estão satisfeitas quanto à divisão do trabalho.

Quanto à participação nas reuniões, oito responderam que sempre vão às reuniões e um respondeu que participa sempre quando há importantes decisões. Quanto à participação nas decisões da cooperativa, seis responderam que participam ativamente, sempre se posicionando e expondo seu ponto de vista, enquanto que três afirmam que depende, em algumas situações apresentam suas ideias e em outras não. É bom ressaltar que todas as decisões tomadas na cooperativa são feitas por meio de consenso. Somente quando não há consenso, 0 que, segundo as informações obtidas, só aconteceu uma vez, a decisão é tomada em votação.

Quanto à produção, todos concordam que o leite é o principal produto comercializado pela cooperativa. Mas alguns dão atenção também às hortaliças, sucos e outros produtos agroecológicos que eles comercializam, principalmente em feiras específicas deste tipo de produto. 


\subsection{Questões aplicadas especificamente aos agricultores dos lotes individuais}

Quanto ao grupo individual, foram entrevistadas 25 famílias das 33 que estão no assentamento. Nenhuma família participa de outra cooperativa como cooperada e todos também sempre trabalharam com agricultura e são descendentes de agricultores. Alguns agricultores não foram entrevistados, ou por não terem sido encontrados, ou por não estarem disponíveis.

A produção somente para o autoconsumo aparece para três famílias das 25 entrevistadas. Essas famílias recebem aposentadoria do casal e são constituídas de pessoas com mais de 50 anos, o que dificulta o trabalho na agricultura. Assim, as questões relativas aos produtos comercializados foram respondidas pelas 22 famílias restantes (figuras 1 e 2).

A tomada de decisão nos lotes individuais é feita apenas com o casal em 13 unidades. Em 10 unidades decidem entre a família (casal e filhos) e em duas unidades o agricultor toma decisões sozinho.

Na figura 1, é apresentado um gráfico mostrando os principais produtos comercializados. Quanto à comercialização de produtos, 16 famílias produzem leite para comercialização, cujo excedente (que não foi consumido pela família) é vendido para a COOPAVA. Três produtores trabalham com a produção de sementes, vendendo-as para a BIONATUR, que é uma cooperativa de sementes agroecológicas vinculada ao MST. Outros produtos como feijão e milho também são comercializados por algumas famílias. Todos estes produtos são típicos da agricultura familiar (veja IBGE, 2009).

O que é importante ressaltar nesse ponto é que, entre 22 famílias que produzem para comercializar algum produto, sete possuem renda de somente um produto, pois tem-se somente 15 respostas para a produção do segundo produto. Assim como para o terceiro produto, das 15 famílias que produzem pelo menos dois produtos, somente quatro famílias citam o terceiro produto, o que resulta em 11 que produzem somente dois produtos para a comercialização. A existência de um produto principal e outros secundários para venda, ou simplesmente para auto consumo, é uma estratégia muito comum entre os agricultores familiares, tendo sido constatado por outros autores como Gasson(1973), Abramovay(1992) e Lima et al.(2005). Além disso, a venda de excedentes é um comportamento que converge com aquele descrito em Abramovay(1992) e Payés e Silveira(1997) e que representa uma estratégia de integração reversível ao mercado, parecida com a do camponês Chayanoviano.

Esse resultado também pode ser consequência da dificuldade de mão de obra, do espaço limitado ou talvez do risco advindo de iniciar a produção de algo e não ter a disponibilidade de dedicação necessária para tê-lo como principal produto. A maioria tem a renda estável como principal motivo de produção do produto (veja figura 2) e também deve ser considerado que algumas famílias se separaram do grupo coletivo recentemente, o que pode gerar falta de capital para investimento imediato na produção. Situação similar é descrita em Xavier(2010). 
Figura 1. Principais produtos comercializados pelos agricultores dos lotes individuais

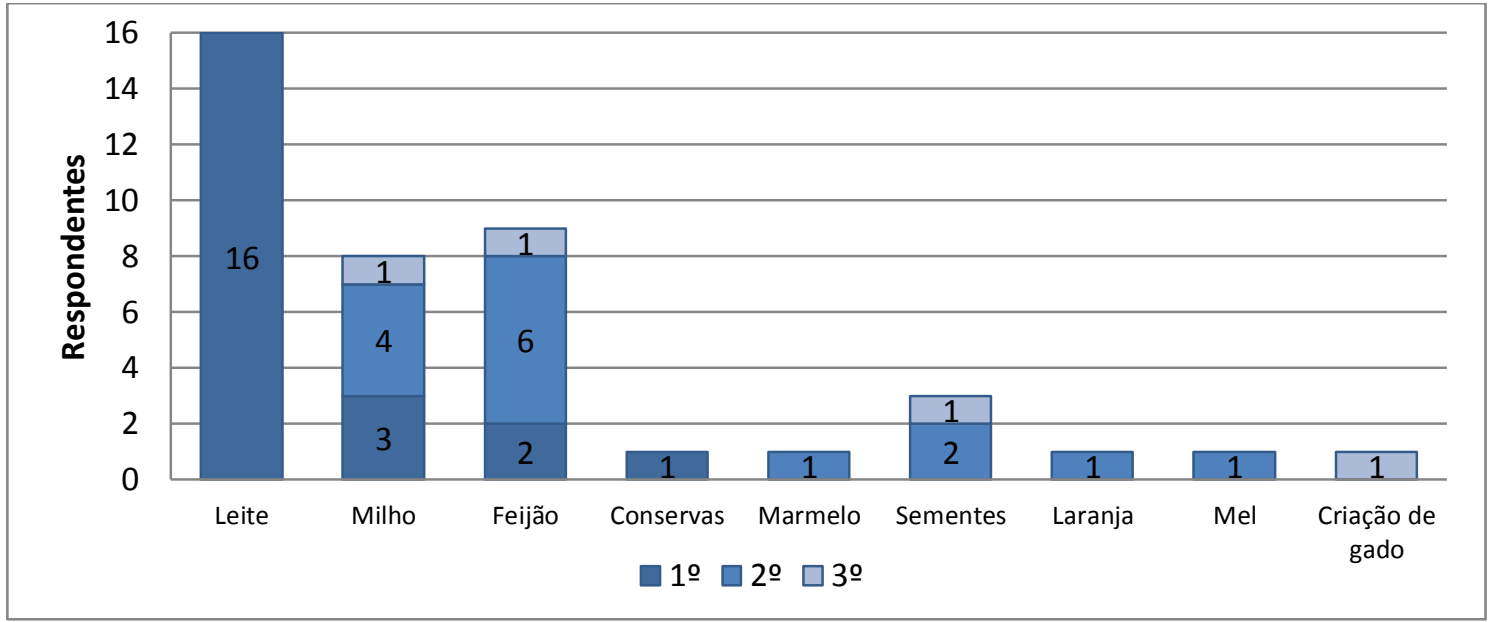

Fonte: Elaboração com base nos resultados da pesquisa.

O motivo da produção do principal produto da unidade de produção é apresentado na figura 2. A renda estável é a principal motivação para a produção do leite. Nove famílias apontam esse como principal motivo, seguido da questão de limitação da área, citado por seis famílias. O clima da região e o maior benefício econômico são apontados uma vez cada um.

Figura 2. Relação do principal produto produzido com o principal motivo para produção deste

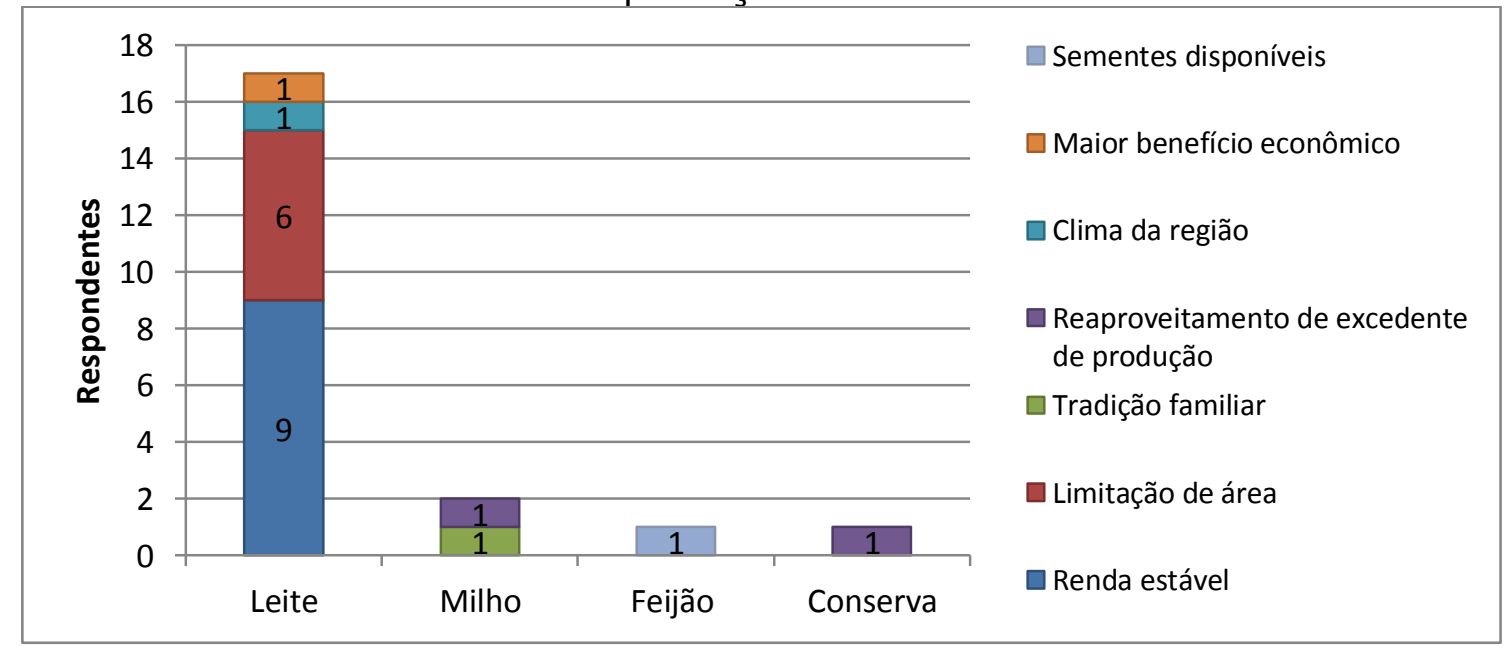

Fonte: Elaboração com base nos resultados da pesquisa.

A produção de milho, segundo principal produto mais comercializado, é justificada por uma família como um produto que, além da venda, o excedente serve como alimentação para os animais da unidade; para outra família sua produção é motivada pela tradição familiar. A produção de feijão é motivada por possuírem sementes disponíveis para a plantação e a conserva de alimentos é pelo reaproveitamento do excedente da produção. A produção de milho e o aproveitamento de outros excedentes, além de fonte de renda secundária, tem 
papel importante na segurança alimentar como apontam os estudos de Grisa(2007) e Ploeg(2008).

A figura 3 apresenta o gráfico relativo às principais preocupações quanto à condução da propriedade. Nessa questão, o produtor poderia escolher tantas opções quantas achasse relevante e deveria posicioná-las em ordem de importância. Importa destacar a concentração de respostas na "Renda estável" e "Preços de produtos e insumos" como principais preocupações desses agricultores. Esses fatores apontados mostram o quão sensíveis os agricultores são frente ao risco/incerteza associado às suas fontes de renda. A racionalidade subjacente aqui também emergiu em outros estudos de natureza empírica, como os de Xavier(2010) e Reichert e Gomes(2013) e Silva et al.(2013). Bastante interessante foi constatar que a "Mão de obra disponível" foi apontada como elemento importante por apenas um agricultor. Apesar de Saco dos Anjos e Caldas (2005) destacarem as tendências recentes de envelhecimento e diminuição do tamanho das famílias como elemento de restrição da força de trabalho, talvez esta escassez tenha sido relativizada na mente dos agricultores frente à incerteza em relação a outros aspectos mais importantes e restritivos na tomada de decisão, como a renda estável e preços de insumos e produtos.

Figura 3. Principais preocupações dos agricultores dos lotes individuais para a gestão do lote.

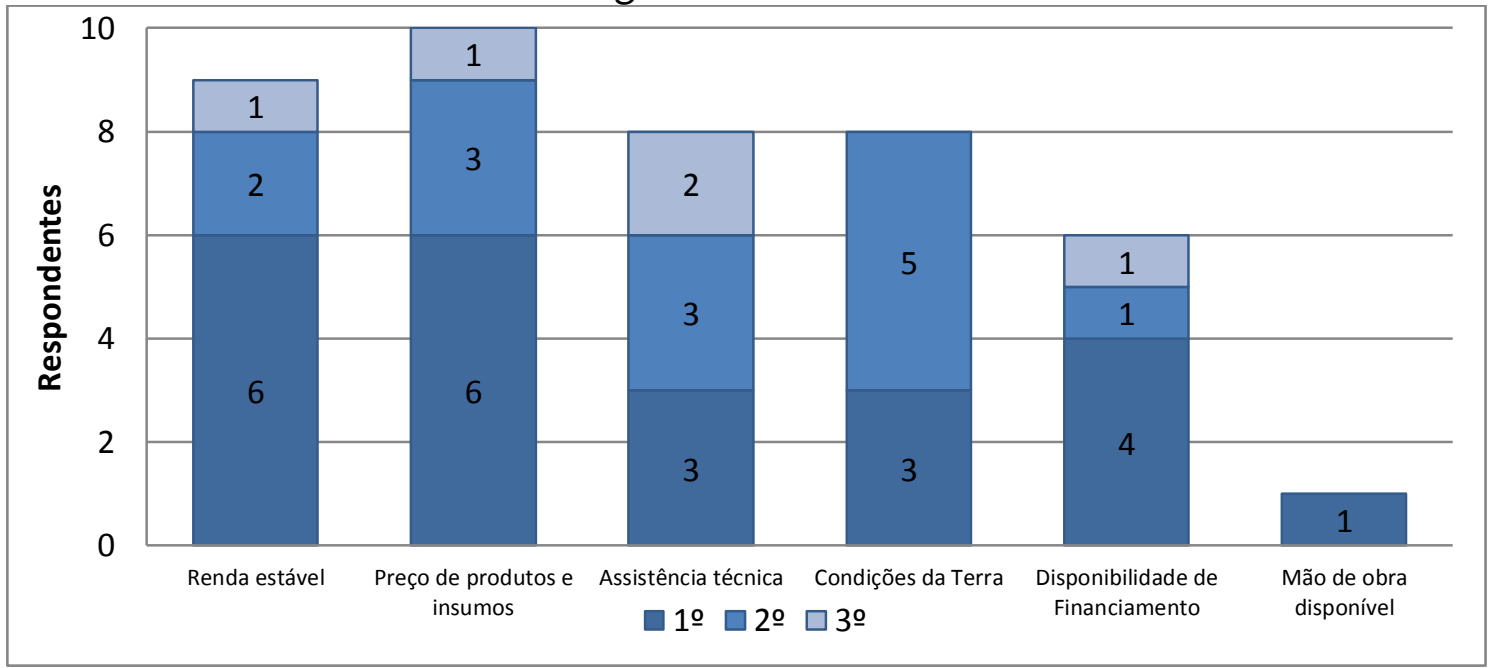

Fonte: Elaboração com base nos resultados da pesquisa.

\subsection{Questões aplicadas para todos os assentados}

As questões aplicadas para todos os assentados são relativas ao seu perfil geral e também às informações às quais produtores têm acesso e o quanto elas influenciam suas decisões. Foram 34 entrevistados, sendo que 9 trabalham coletivamente (cooperados) e 25 têm suas próprias unidades de produção (lotes individuais).

Na tabela 1, é apresentada a relação de escolaridade no assentamento, onde o nível de escolaridade até a $5^{\text {a }}$ série do Ensino Fundamental predomina nos dois grupos (cooperados e individuais) com 5 e 16 respondentes, respectivamente. A seguir, o nível de escolaridade Educação de Jovens e Adultos - EJA, direcionada 
ao MST, ocorre em um caso entre os respondentes da cooperativa e em três dos lotes individuais.

Tabela 1. Escolaridade dos agricultores Cooperados e Individuais do assentamento Conquista da Liberdade

\begin{tabular}{lcc}
\hline \multicolumn{1}{c}{ Grau de escolaridade } & Cooperados & Individuais \\
\hline Nunca estudou & 0 & 2 \\
Primeira série do Ensino Fundamental & 0 & 2 \\
Até a 5a série do Ensino Fundamental & 5 & 16 \\
Ensino de Jovens e Adultos - MST & 1 & 3 \\
Ensino Médio completo & 2 & 0 \\
Técnico em Contabilidade & 1 & 0 \\
Técnico Agrícola & 0 & 1 \\
Pós Graduação & 0 & 1 \\
\hline
\end{tabular}

Fonte: Dados da pesquisa.

Na tabela 2, é apresentada a máxima escolaridade dos filhos da família, tendo-se optado por identificar somente a escolaridade máxima alcançada entre os filhos. Pode-se notar que o Ensino Técnico na área agrícola é bastante presente para as famílias dos dois grupos, uma vez que os que estão cursando e os que já completaram somam 12 respondentes; o Ensino Superior de graduação (cursando ou já completado) é outro destaque com seis pessoas. Cabe ressaltar que, no assentamento, há uma escola de Ensino Fundamental com aulas até a $5^{\mathrm{a}}$ série. Após esse nível, as crianças devem ser direcionadas a outra escola, com disponibilidade de transporte. Também há, nas cidades vizinhas, escolas técnicas agrícolas que possuem alojamento, escolhidas pela maioria das crianças que seguem para o Ensino Médio.

Tabela 2. Máxima escolaridade dos Filhos dos agricultores Cooperados e Individuais do Assentamento Conquista da Liberdade

\begin{tabular}{lcc}
\hline Grau de escolaridade & Cooperado & Individual \\
\hline Não possui filhos & 0 & 3 \\
Não estudam & 0 & 3 \\
Até 5a série do Ensino Fundamental & 0 & 1 \\
Cursando Ensino Fundamental & 0 & 5 \\
Ensino Fundamental completo & 0 & 4 \\
Cursando Ensino Tecnológico na área & 3 & 1 \\
Ensino Tecnológico completo na área & 2 & 6 \\
Cursando Ensino Superior na área & 2 & 2 \\
Ensino Superior completo na área & 1 & 0 \\
Ensino Superior em outra área & 1 & 0 \\
\hline
\end{tabular}

Fonte: Dados da pesquisa.

Uma das estratégias fundamentais de reprodução na agricultura familiar é a diversificação de fontes de renda (SCHNEIDER, 2003). A tabela 3 resume as distintas fontes encontradas. Sem entrar na discussão sobre o caráter compensatório da política de seguridade social para a agricultura, percebe-se como a aposentadoria transformou-se em uma fonte extra de renda muito comum entre os agricultores familiares, impulsionada pelo envelhecimento já comentado anteriormente, inclusive com unidades onde o produtor e sua esposa recebem o 
benefício. Além da aposentadoria, a venda de força de trabalho em uma plantação de soja fora do assentamento foi relatada como fonte externa de renda.

Tabela 3. Fontes de renda dos agricultores Cooperados e Individuais do Assentamento Conquista da Liberdade

\begin{tabular}{lcc}
\hline Fonte & Cooperado & Individual \\
\hline Exclusivamente da agricultura & 6 & 13 \\
Uma aposentadoria & 2 & 5 \\
Duas aposentadorias & 1 & 5 \\
Trabalho fora (plantação de soja) & 0 & 2 \\
\hline
\end{tabular}

Fonte: Dados da pesquisa.

O relacionamento entre os agricultores do assentamento e algumas instituições comuns da região também foi avaliado. A figura 4 apresenta um retrato com um pouco mais de detalhe desta avaliação onde os agricultores expressaram sua percepção de quão frequente é o auxílio recebido de técnicos da Empresa Brasileira de Pesquisa Agropecuária - EMBRAPA, EMATER, Instituto de Colonização e Reforma Agrária - INCRA, MST e Universidades. Merece destaque a lembrança dos agricultores da presença da EMATER e de universidades como os agentes institucionais mais presentes no assentamento.

A EMATER, segundo os entrevistados, é o órgão que acompanha e auxilia na produção, disponibilizando visitas periódicas e cursos de aperfeiçoamento da produção para os assentados. Apesar das universidades serem apontadas pelo grupo dos cooperados como visitantes assíduos, nos lotes individuais, nove famílias afirmam não receber visitas delas e 13, que são poucas. Muitos dos entrevistados apontam a universidade como visitas para troca de ideias, mas não como fonte de conhecimento propriamente dito, já que muitos alunos e pesquisadores utilizam suas propriedades para estudos e não retornam com o resultado para auxiliar na produção. As universidades mais lembradas pelos agricultores são a Universidade Federal de Santa Maria - UFSM e a Universidade Federal de Pelotas - UFPel.

Figura 4. Avaliação dos agricultores cooperados e agricultores dos lotes individuais do auxílio dos técnicos na propriedade

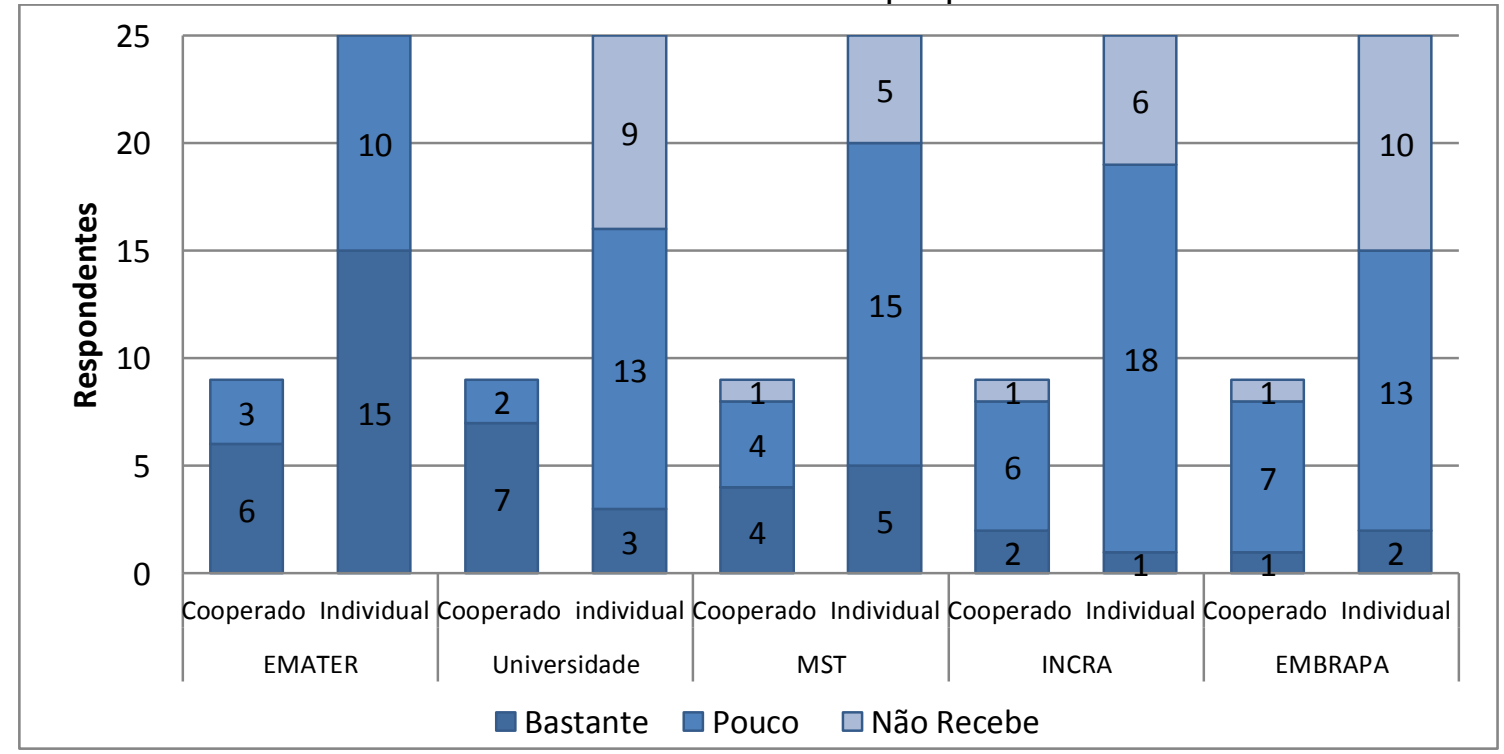

Fonte: Elaboração com base nos resultados da pesquisa. 
Sobre as visitas das instituições, os agricultores foram questionados sobre quais delas desejariam receber mais vezes. A figura 5 mostra que dez entrevistados afirmaram que o auxílio que recebem já é suficiente. Porém, convém salientar que algumas dessas respostas advêm de produtores que produzem somente para a subsistência. Muitos deles acreditam que "os técnicos já têm muitos assentamentos para auxiliar, assim fica difícil para eles virem sempre aqui". Por não visar à comercialização, talvez os produtores percebam a produção de subsistência como menos importante e queiram poupar os técnicos do acompanhamento deste tipo de produto.

Ainda sobre essa questão, o entrevistado poderia citar todas as instituições que deseja receber mais vezes em sua propriedade. A figura 5 mostra também que a EMATER foi a instituição mais lembrada para receber mais auxílio para a produção (18 entrevistados). Apesar de muitos cursos disponibilizados, a falta do acompanhamento posterior é o principal problema mencionado pelos entrevistados.

A EMBRAPA é citada por 13 entrevistados, principalmente porque os técnicos já auxiliaram o assentamento há algum tempo e acrescentaram muito conhecimento e desenvolvimento na produção. As universidades são lembradas por oito agricultores, também por já terem realizado diversos trabalhos com o assentamento. O INCRA foi lembrado em sete entrevistas e o MST em quatro, como auxílio que gostariam de receber mais vezes.

Figura 5. Instituições que os agricultores gostariam de receber mais vezes em sua propriedade.

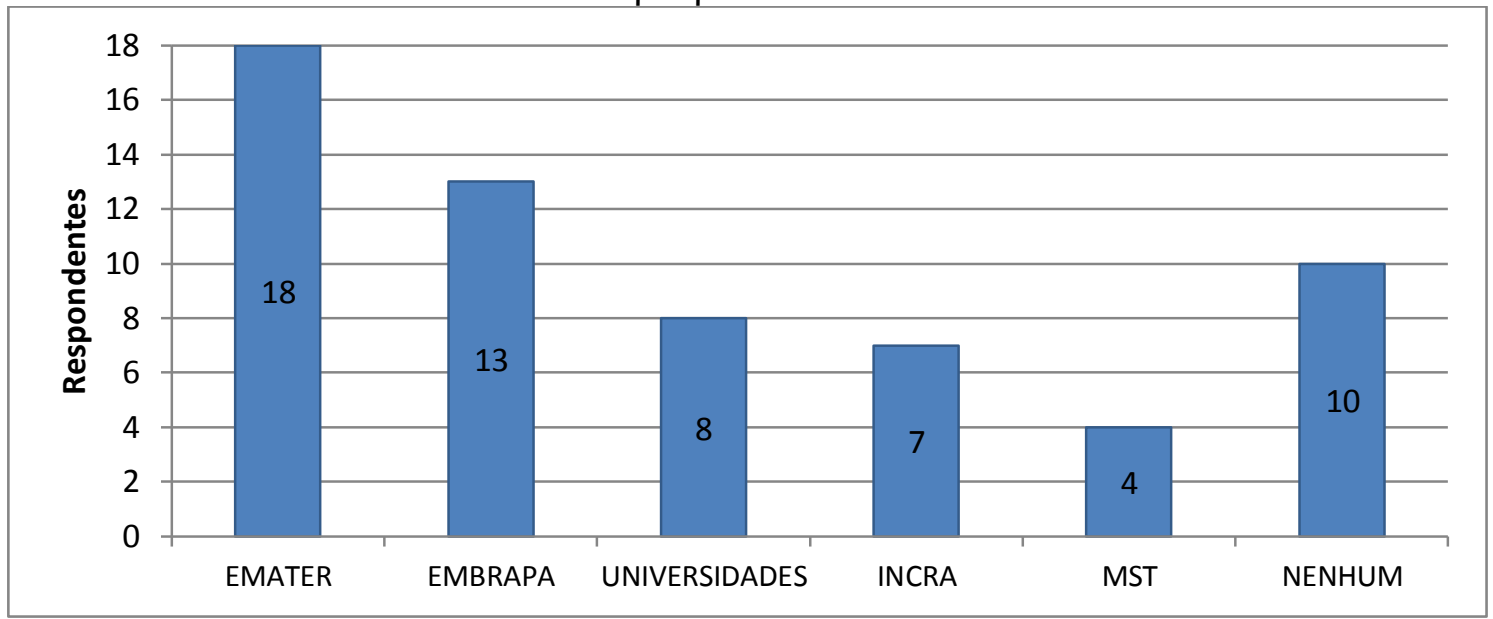

Fonte: Elaboração com base nos resultados da pesquisa.

Essas instituições, além de estabelecerem um relacionamento com os assentados, constituem-se em importantes fornecedores de informação para a tomada de decisão dos agricultores. No entanto, outras fontes desempenham também esse papel. A figura 6 apresenta a ordem de importância dos meios de comunicação influentes na tomada de decisão dos assentados. Os meios de comunicação apontados em maior número em primeiro lugar são os programas rurais na TV, seguido das cartilhas e livros técnicos. Cabe ressaltar que essa questão foi respondida somente pelo entrevistado que apontou pelo menos uma 
opção como muito influente na tomada de decisão com relação à produção agrícola de sua propriedade.

Figura 6. Principais meios de comunicação como fonte de informações para a tomada de decisão

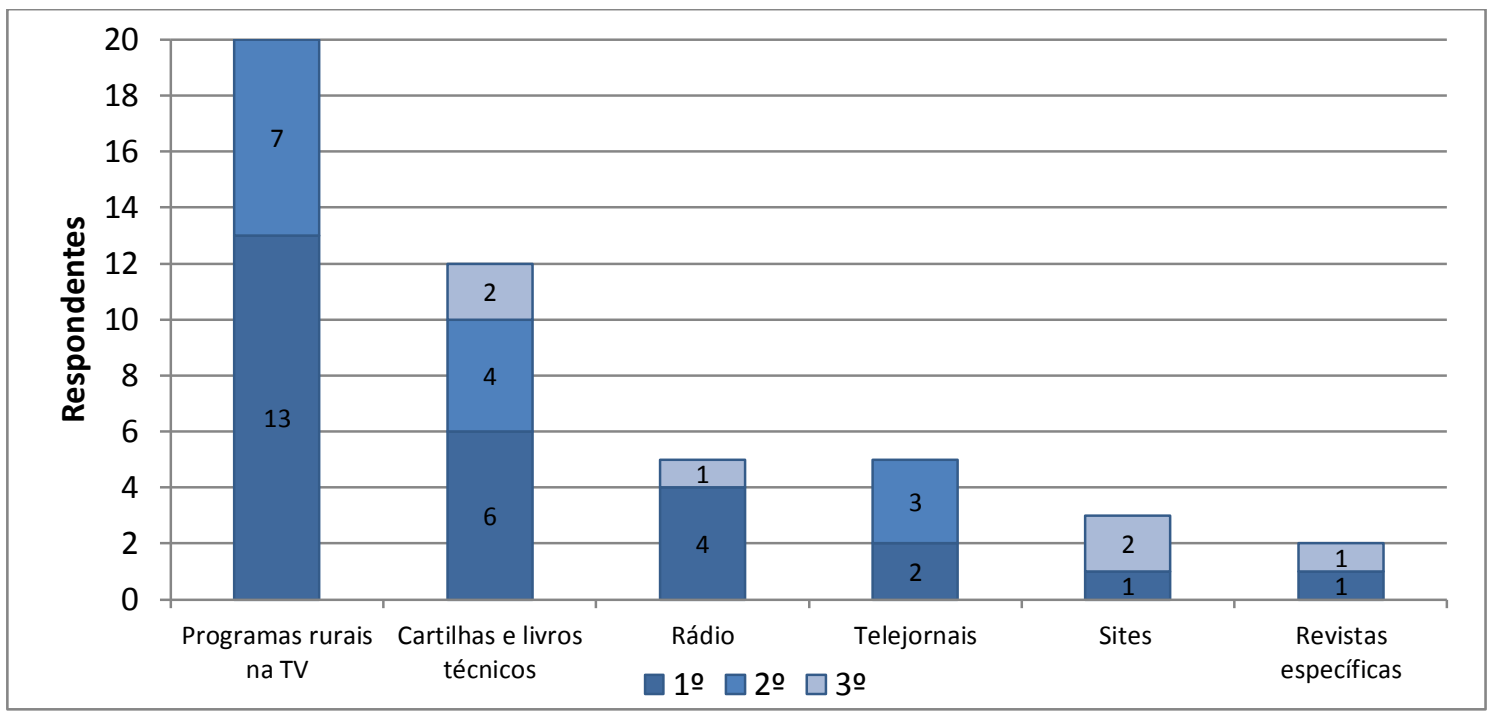

Fonte: Elaboração com base nos resultados da pesquisa.

A figura 7 refina as informações anteriores mostrando a intensidade de influência dos diferentes meios de comunicação na percepção dos distintos tipos de assentados. Destacaram-se os programas rurais de TV como sendo muito influentes na tomada de decisão para ambos, cooperados e individuais, mas em uma proporção maior para os agricultores dos lotes individuais. Os programas mais lembrados foram Globo Rural e Campo e Lavoura.

Outra fonte de informação a destacar são as cartilhas e livros técnicos. Para seis cooperados é uma fonte de informação de grande influência sobre suas decisões. Normalmente, essas cartilhas e publicações são obtidas em cursos ministrados no assentamento, por intermédio da EMATER, universidades, EMBRAPA, entre outras instituições.

É importante destacar que a maior parte dos entrevistados não tem acesso a jornais impressos devido à dificuldade de acesso ao assentamento para entrega regular ou para compra na cidade. Os telejornais são também fontes de informações, porém, apresentam pouca ou nenhuma influência na tomada de decisão com relação à propriedade dos agricultores entrevistados. A maioria deles afirma usar os telejornais somente para previsão do tempo e para atualização de notícias de cunho geral. Machado(1999), em seu trabalho com agricultores espanhóis concluiu que não só a quantidade e qualidade de informação disponível ao produtor foi importante, mas também a capacidade de transformá-la, processála e gerar algo de novo e útil.

Relacionando esses resultados com os resultados apresentados na figura 3, sobre as principais preocupações na condução das atividades, percebe-se a visão de Herbert Simon sobre o que estaria por vir. Na edição de 1997, celebrando o $50^{\circ}$ aniversário da sua obra seminal Administrative Behavior, Simon afirmava que, naquele momento e mais ainda, no futuro, a busca e obtenção de informação não seria uma limitação à tomada de decisão (naquela época a internet apenas 
ensaiava seus primeiros passos). A grande limitação, segundo Simon, era (e ainda é) de decidir qual informação é importante. E isso está associado à capacidade cognitiva do homem que é pequena para analisar e dar sentido à grande quantidade de informações geradas a cada momento. Mesma conclusão a que chegou Machado(1999).

Figura 7. Influência dos meios de comunicação como fonte de informações

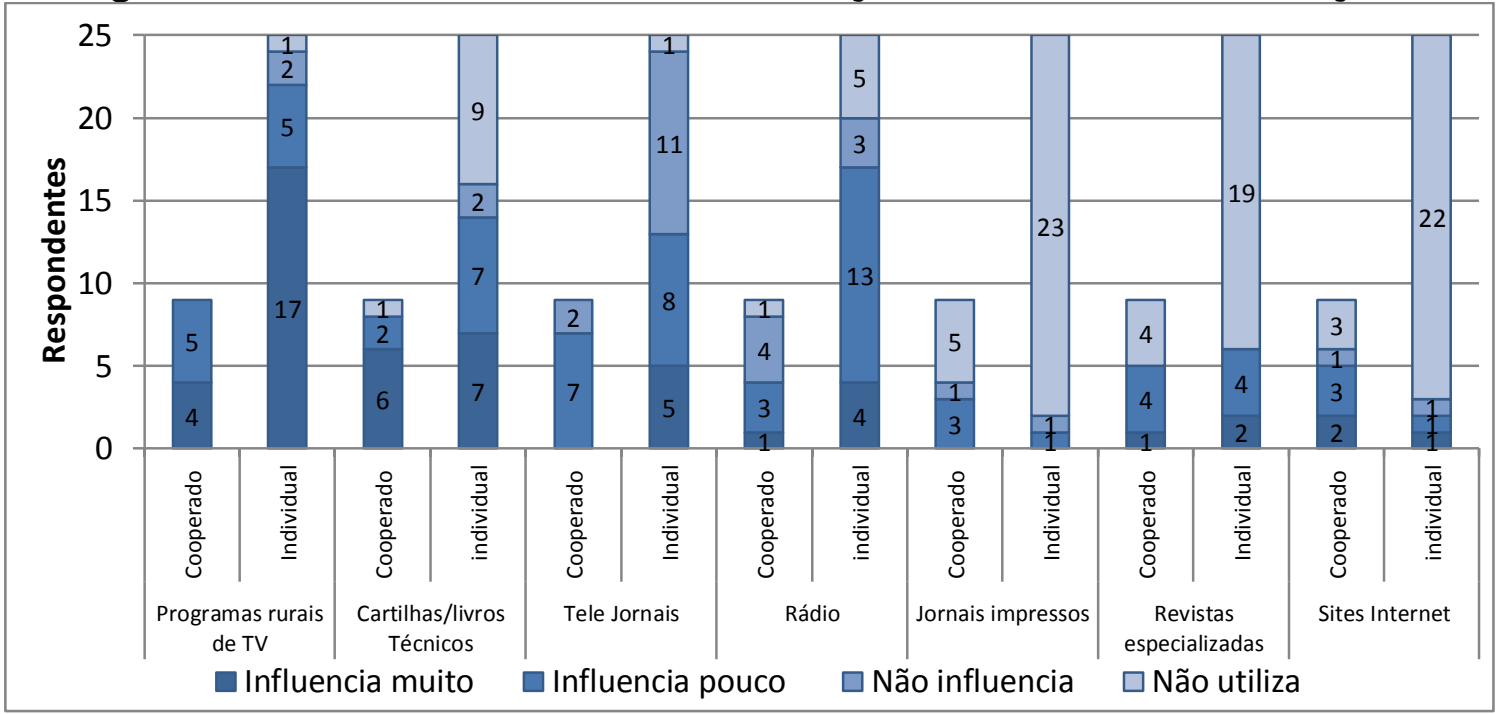

Fonte: Elaboração com base nos resultados da pesquisa.

Há também outras importantes fontes de informações provenientes de outros meios e são apresentadas na figura 8. Por exemplo, a experiência adquirida com a prática mostra-se muito influente nas decisões de ambos os grupos de produtores. Para Caporal e Costabeber (2000), a experiência resulta de saberes empíricos acumulados ao longo do tempo pela família e que se transmitem de geração em geração e se demonstram tão importantes quanto o saber científico. Ploeg (2000) chega à mesma conclusão ao estudar as práticas dos agricultores de batata do altiplano andino.

Os aspectos culturais dos agricultores, como as tradições, foram considerados elementos importantes e influentes na tomada de decisão. Talvez o fato de seguir a tradição da comunidade ou da família seja uma maneira de enfrentar as incertezas e riscos na tomada de decisão. Em contextos de incapacidade de julgar as informações que se possui ou mesmo na falta de informação, essa tende a ser a válvula de escape.

Os cursos e palestras sobre agricultura constituem-se em outra fonte de informação importante nas suas decisões. Em certa medida, Gasson(1973); Errington(1986) e Solano et al.(2003) afirmam que o agricultor muitas vezes procura cercar-se de pessoas nas quais possa confiar (confiáveis) e que, de certa forma, se constituam-se em um aval para a informação que recebem. É um sistema baseado na reputação das pessoas e elas podem ser outros agricultores (vizinhos), consultores, técnicos, pesquisadores, professores e até membros da própria família.

Analisando separadamente os cooperados dos lotes individuais, nota-se alguma diferença de percepção. Para os agricultores dos lotes individuais, a fonte com frequência mais alta apontada como muito influente é a experiência, seguida da fonte provinda da cultura. Já para os cooperados, a fonte de informação citada 
mais vezes é a que vem de cursos e palestras, experiência e o auxílio dos técnicos, seguidas das informações advindas das universidades. Percebe-se a presença mais forte dos técnicos na cooperativa e o quanto eles influenciam mais nesse grupo.

Figura 8. Influência das fontes de informação na tomada de decisão no que se refere à agricultura

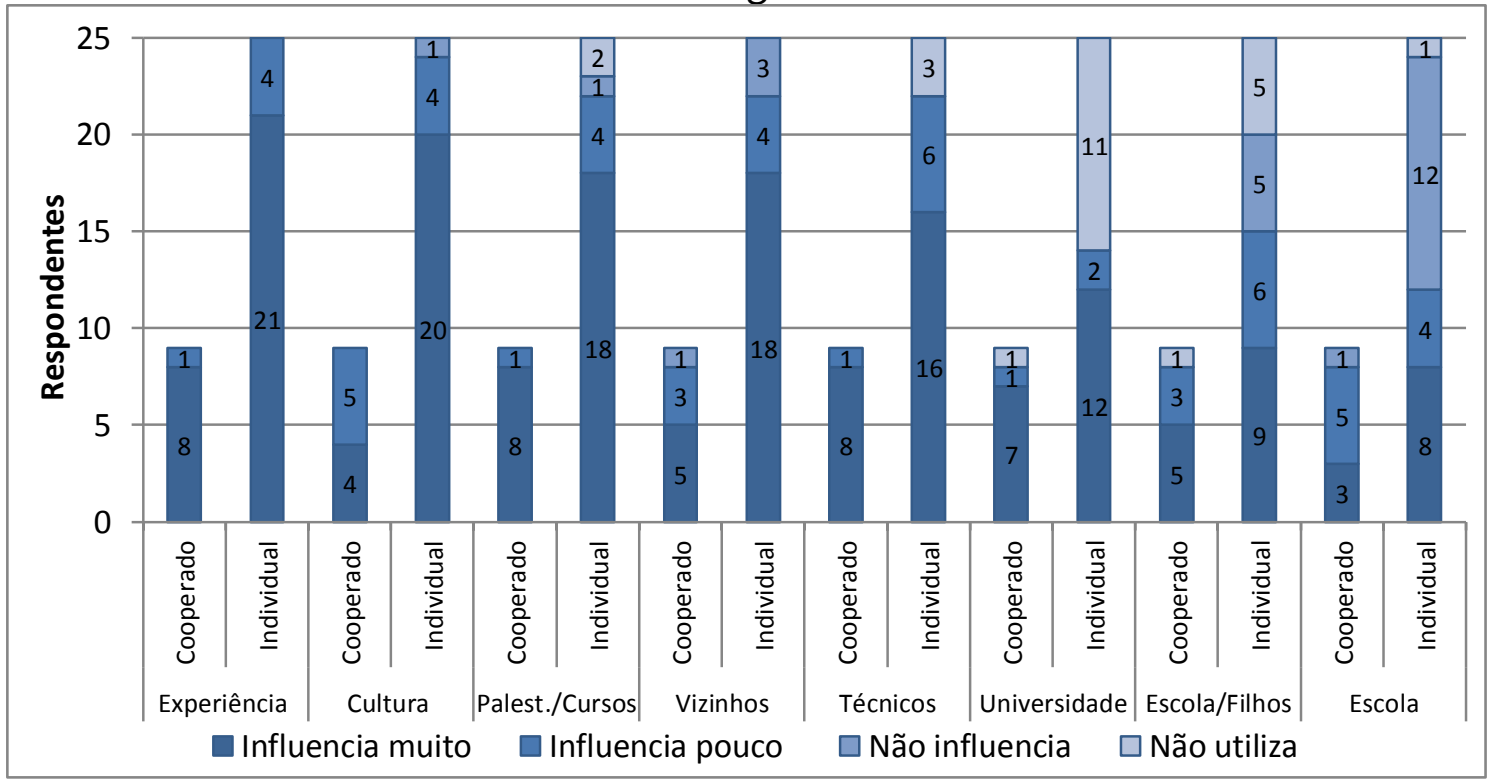

Fonte: Elaboração com base nos resultados da pesquisa.

É interessante citar, nesse ponto, o trabalho de Teixeira e Lima(1993) que afirmam que o conhecimento adquirido pela prática dos produtores é o alicerce para os pequenos agricultores com relação à sua produção diante das imposições do mercado e da própria natureza. Nesta pesquisa, a experiência adquirida por meio da prática aparece como principal fonte de influência sobre a tomada de decisão dos agricultores.

Nesse cenário, onde há meios de comunicação não confiáveis, apontado pelo baixo nível de influência sobre as decisões dos agricultores, pode-se remeter ao trabalho de Ford e Babb (1989) e Sutherland et al. (1996) que constataram que as fontes de informações escritas são vistas como imprecisas, impessoais e não específicas pelos agricultores. No entanto, as cartilhas, nesse grupo, são vistas como uma fonte mais pessoal por serem adquiridas em cursos e diretamente dos técnicos. Os programas rurais, apesar dos agricultores mencionarem que muitos deles estão direcionados a grandes produtores, são percebidos em um contexto mais próximo e ao alcance do assentado.

As fontes classificadas como muito influentes foram ordenadas por importância pelos entrevistados, representadas pela figura 9. Essa questão foi respondida pelos entrevistados que consideraram pelo menos uma fonte de informação como muito influente na sua tomada de decisão. Tanto no caso dos cooperados quanto dos lotes individuais, os agricultores citam em primeiro lugar as informações adquiridas pelos técnicos, mas numa proporção maior para o grupo dos cooperados. Já no grupo individual, há uma dispersão maior entre os Técnicos, Cultura e Experiência. Para o segundo lugar, a fonte mais citada, foi palestras e cursos, seguida dos técnicos e experiência. Para o terceiro lugar em fontes de 
informações influentes aparece palestras e cursos como a mais citada seguida da experiência.

Assim, é possível verificar a importância das informações advindas dos técnicos e dos cursos e palestras, citadas em todas as ordens, além da experiência que aparenta ser uma fonte bastante influente para esses agricultores. Apesar de ser citada poucas vezes, a cultura aparece mais frequentemente para os lotes individuais entre as três fontes mais influentes na tomada de decisão. Também nessa mesma situação, aparece a escola do filho como fonte de informação, citada poucas vezes, porém, aparece entre as três fontes principais de informações, o que aponta certa importância da escolaridade do filho nas famílias dos assentados.

Figura 9. Importância das principais fontes de informações para os agricultores assentados

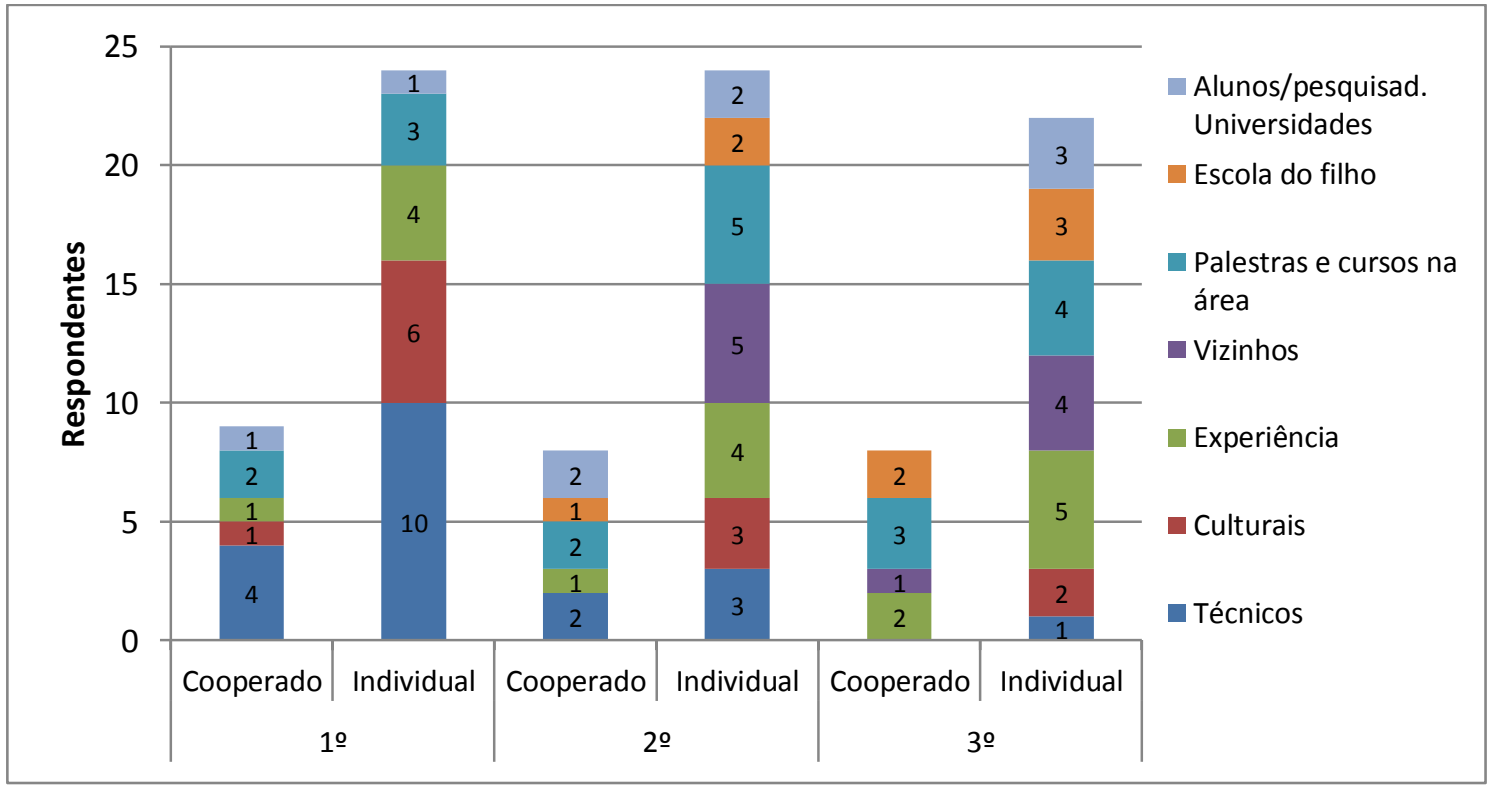

Fonte: Elaboração com base nos dados da pesquisa.

Dessa forma, não só a informação em si é importante, mas a fonte da informação desempenha um papel na tomada de decisão. A incerteza só pode ser diminuída com informação, e a tabela 3 aponta a quem os cooperados e os produtores individuais recorrem em situação de risco ou quando necessitam de alguma informação que desconheçam com relação ou às suas propriedades ou suas produções.

Alguns relutaram a responder, por acreditarem que só os conhecimentos que já possuem são suficientes para tomar todas as decisões no que tange à agricultura. Porém, pode-se notar que, junto com as informações que se originam de sua própria experiência, emergem as adquiridas por meio dos cursos e palestras, e após aparecem as culturais e as adquiridas por meio dos técnicos, o que mostra uma parcela importante de participação do conhecimento externo no desenvolvimento de grande parte dessas famílias.

Grande parte dos agricultores, cooperados e individuais, costumam buscar na EMATER as respostas que necessitam em situações de risco e incerteza, ou quando precisam de alguma informação em relação a suas propriedades e 
produções. Em menor quantidade, para os individuais e para os cooperados, aparecem os vizinhos.

Esses resultados são convergentes com os de Ford e Babb (1989) e Sutherland (1996), onde os agricultores apresentaram preferência pelas fontes de informações pessoais por acreditarem ser mais precisas. Nesses mesmos trabalhos, aparecem os extensionistas como papel indispensável na informação e no desenvolvimento das unidades de produção. No presente trabalho aparecem igualmente com grande importância para os produtores rurais.

Tabela 4. Busca de informações em condições de incerteza e risco

\begin{tabular}{|c|c|c|c|c|}
\hline \multirow{2}{*}{$\begin{array}{l}\text { Agricultor } \\
\text { Assentado }\end{array}$} & \multicolumn{4}{|c|}{$\begin{array}{l}\text { A quem recorre em uma situação de risco/incerteza ou quando } \\
\text { precisa de informações }\end{array}$} \\
\hline & Vizinhos & COOPAVA & $\begin{array}{l}\text { Técnicos } \\
\text { EMATER }\end{array}$ & Agropecuária \\
\hline Cooperado & 1 & 3 & 5 & 0 \\
\hline Individual & 5 & 0 & 19 & 1 \\
\hline
\end{tabular}

Fonte: Elaborado com base nos dados da pesquisa.

Por fim, também são importantes as informações a respeito do preço dos produtos. Essa informação está diretamente ligada, primeiro, à geração de receitas que é o resultado de todo esforço produtivo; e segundo, porque o preço introduz um componente de incerteza na tomada de decisão. Apesar dos elementos influentes na tomada de decisão serem diversificados, o componente econômico é importante.

A figura 10 apresenta a fonte utilizada pelos agricultores para se informar sobre o preço do produto comercializado. O mercado é a fonte predominante dentre os cooperados. Cinco deles afirmaram ser sua principal fonte de informação sobre os preços, seguido da própria cooperativa, que foi citada por três agricultores, e uma pessoa afirma se informar através dos meios de comunicação, como TV ou rádio. Para os lotes individuais, o predominante é a cooperativa. Onde 10 deles apresentam essa fonte para a informação do preço do produto, seguido do mercado, utilizado por oito deles. Os meios de comunicação são apresentados por três dos assentados e a própria associação dos lotes individuais é citado por um deles.

No geral, tanto o mercado quanto a cooperativa receberam 13 respostas cada, colocando essas fontes como sendo as mais utilizadas para a informação sobre o preço do produto comercializado. Muitos dos entrevistados afirmam não saber o valor de seus produtos no mercado, e outros não têm controle sobre os custos para verificarem o valor que recebem por ele. Com isso, somente aceitam o valor que a cooperativa ou o próprio comprador oferece. 
Figura 10. Fonte de informação sobre o preço do produto comercializado

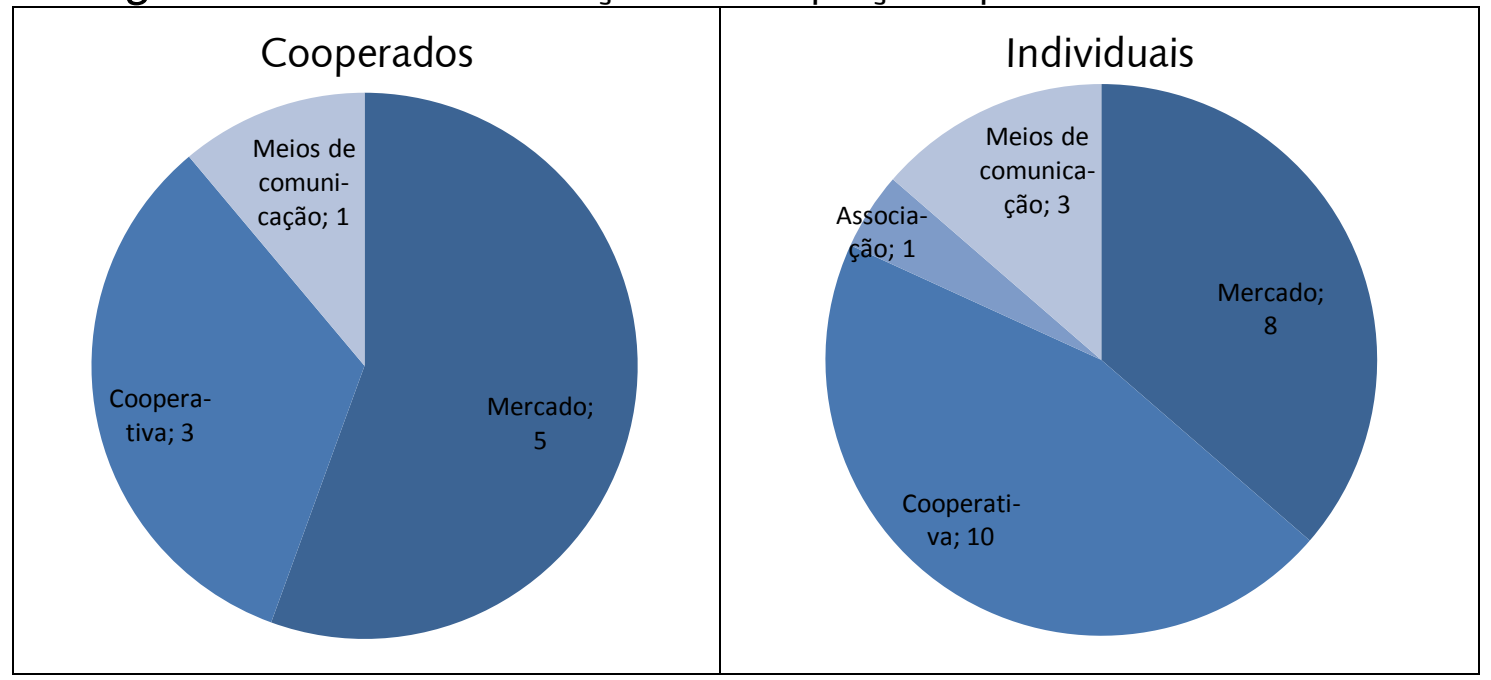

Fonte: Elaboração com base nos resultados da pesquisa

\section{CONSIDERAÇÕES FINAIS}

O estudo proposto serviu para entender melhor o papel das fontes de informação no complexo processo decisório dos agricultores do Assentamento Conquista da Liberdade, tanto para a parte que trabalha coletivamente quanto para a parte dos lotes individuais.

Quanto aos cooperados da COOPAVA, todos se colocam como participantes das decisões. Considerando que há pouco tempo algumas famílias optaram por lotes individuais, gerando aumento da carga de trabalho para as que permaneceram, a maioria afirma que a distribuição do trabalho deve melhorar. $\mathrm{O}$ leite foi identificado como principal produto comercializado pela cooperativa.

Nas produções individuais, as decisões são tomadas pelo casal na maioria das famílias entrevistadas. Com relação aos produtos comercializados, o leite é o principal produto para a maioria das propriedades, e é importante ressaltar que somente quatro famílias produzem mais de dois produtos para a comercialização, mostrando a dificuldade desses produtores em expandir a diversificação da produção. O motivo mais citado para a decisão de escolha da produção é a renda estável. Isso explica a escolha do leite como principal produto para comercialização, já que ele proporciona renda o ano inteiro e possui mercado certo.

Os resultados do questionário apontam que grande parte dos agricultores estudados depende somente da agricultura para sobreviver. Apesar da baixa escolaridade, cabe salientar que a escolaridade dos filhos (uma parcela estuda em escolas técnicas agrícolas e alguns cursam nível superior) começa a aportar informação para o processo decisório.

Com os resultados, foi possível identificar a importância da EMATER no desenvolvimento e disseminação da informação para esses produtores e a grande influência que ela provoca nas decisões dos mesmos. Também foi possível constatar o interesse agricultores em receber mais auxílio e informações por meio da EMBRAPA, da EMATER e universidades. Entretanto, algumas famílias se mostram satisfeitas com o auxilio que já recebem, reconhecendo o esforço da 
EMATER. Outros agricultores declararam que já sabem o suficiente, como foi discutido ao longo do trabalho.

Com relação aos meios de comunicação como fonte de informações, os mais influentes entre os agricultores são os programas rurais que passam pela televisão. Em segundo lugar, aparecem as cartilhas e livros técnicos, também oriundos dos cursos ministrados no assentamento, o que aponta uma importante opção para a ajuda no desenvolvimento dos agricultores familiares.

As informações com maior participação no cotidiano dos agricultores não são as provindas de meios de comunicação. Além de sua própria experiência na agricultura, as decisões são influenciadas pelas informações adquiridas nos cursos e nas palestras ministrados por técnicos, pela sua cultura - transmitida pelos ascendentes - e por informações trazidas pelos técnicos. Nesse ponto, o que se pode notar é a importância dos técnicos e extensionistas no assentamento. Além da assistência direta, que é uma forte fonte de informações, proporcionam cursos que colaboram muito com o desenvolvimento produtivo.

Ordenadas por importância, as informações mais citadas nos primeiros lugares são as adquiridas por intermédio dos técnicos, culturais, experiência e cursos na área, o que coloca esse grupo como aberto a receber novas informações.

Em se tratando de situações de risco e incertezas com relação à produção, a grande maioria dos entrevistados busca informações e auxílio técnico diretamente com os técnicos da EMATER. E o preço dos produtos comercializados é informado pelo próprio mercado ou pela cooperativa.

Esse estudo mostrou que, em se tratando de informações para esses agricultores, há maior influência das próprias experiências. No entanto, mostramse interessados em adquirir mais conhecimento por meio de cursos e apoio técnico, seja por intermédio da EMATER ou da EMBRAPA, contanto que possuam a segurança de ter acompanhamento em suas produções para diminuir o risco.

A tomada de decisão no meio rural, sobretudo no que tange à agricultura familiar, é complexa, principalmente pelos riscos que ela impõe. Estudos voltados a essa questão podem servir como apoio no aprimoramento e colaboração de meios de acesso a mais informações para os agricultores, com a finalidade de tentar amenizar a dificuldade da questão. Este trabalho serviu para entender melhor esse tema, com o intuito de mostrar alternativas para o desenvolvimento econômico e social da agricultura familiar, apontando os meios de informação mais eficazes para esses produtores.

Por fim, apesar do foco central do trabalho estar direcionado para a informação e o processo decisório, é possível tecer alguns comentários sobre a necessidade de informação, o processo decisório, o desempenho produtivo em assentamentos e o desenvolvimento territorial. Há um programa do Ministério do Desenvolvimento Agrário voltado para o Desenvolvimento Territorial: o Programa Territórios da Cidadania. Esse programa está voltado para as zonas mais precárias e a delimitação dos Territórios funciona no sentido de identificar essas áreas mais carentes, com baixo Índice de Desenvolvimento Humano - IDH, maior concentração de assentados de reforma agrária, agricultores familiares, entre outros.

Tipicamente nesses Territórios, muitas áreas de assentamento não ficam longe somente das estradas, da infraestrutura, da assistência técnica, mas também das fontes de informação. Desassistidos, esses produtores enfrentam um ambiente 
de muita incerteza e as informações básicas para o processo decisório serão tipicamente de origem interna (experiência própria, vizinhos e na cultura). No entanto, esse é o padrão da tomada de decisão que tende a reproduzir uma situação de pobreza e exclusão. A melhoria das condições de vida dessas comunidades necessita incorporar informação nova capaz de impulsionar e sustentar um processo de desenvolvimento. Daí a importância dos agentes de extensão que procuram, por meio da sua bagagem de conhecimentos, criar vínculos com os agricultores, construir relações de confiança que facilitam o trânsito das informações. Com isso, torna-se possível criar-se um círculo virtuoso de boas decisões em projetos e de transformações que poderiam alimentar o próprio processo de desenvolvimento do assentamento e do território.

Para trabalhos futuros, sugere-se a amplitude de amostragem (outros assentamentos) e comparação com outros resultados empíricos como forma de caracterizar as regiões. Dessa forma, será possível gerar um melhor entendimento do processo de tomada de decisão na agricultura familiar em assentamentos e, principalmente, colaborar com esses produtores que têm grande importância no cenário econômico do país.

\section{AGRADECIMENTO}

Este trabalho foi finalizado e revisado durante o período de Estágio PósDoutoral do segundo autor no Instituto de Estudios Sociales Avanzados, em Córdoba/Espanha. Assim sendo, gostaríamos de registrar nosso agradecimento à CAPES - Coordenação de Aperfeiçoamento de Pessoal de Nível Superior, pela bolsa concedida para este período de estudos (processo no 99999.002489/201505), bem como ao Instituto de Estudios Sociales Avanzados.

\section{REFERÊNCIAS}

ABRAMOVAY, R. Paradigmas do Capitalismo Agrário em Questão. São Paulo, Hucitec/Edunicamp/ANPOCS, 1992.

BAIARDI, A.; ALENCAR, C. M. M. Agricultura familiar, seu interesse acadêmico, sua lógica constitutiva e sua resiliência no Brasil. Rev. Econ. Sociol.

Rural, vol.52, supl.1, Brasília, 2014.

BIO, B. F. Sistemas de informação: um enfoque gerencial. São Paulo: Atlas. 1988.

BRASIL. // Plano Nacional de Reforma Agrária: paz produção e qualidade de vida no meio rural. Brasília, MDA/INCRA/NEAD, 2004. Disponível em:

<http://sistemas.mda.gov.br/arquivos/PNRA_2004.pdf>

CAPORAL, Francisco Roberto; COATABEBER, José Antônio. Agorecologia e desenvolvimento rural sustentável: perspectivas para uma nova extensão rural. Porto Alegre: EMATER/RS-ASCAR. 2000

CHAYANOV, A. V. La organización de la unidad económica campesina. Buenos Aires: Nueva Visión, 1974. 
DEWEY, J. Como pensamos. São Paulo: Editora Nacional, 1953.

ERRINGTON, A. The delegation of decisions on the farm. Agricultural Systems. V.19, p. 299-317. 1986.

FORD, S.A., BABB, E.Y. Farmers sources and use of information. Agribusiness. V. 5, p. 465-476. 1989.

FREITAS, H. M. R; BECKER, J. L.; KLADIS, C. M.; HOPPEN, N. Informação e Decisão: sistemas de apoio e seu impacto.Porto Alegre, Ed. Ortiz, 1997.

GASSON, R. Goals and values of farmers. Journal of Agricultural Economics, v. 24, n. 3, p. 521-542, 1973.

GRISA, C. A produção "pro gasto": um estudo comparativo do autoconsumo no Rio Grande do Sul. 2007. Dissertação (Mestrado) - Universidade Federal do Rio Grande do Sul, Rio Grande do Sul, 2007.

IBGE - INSTITUTO BRASILEIRO DE GEOGRAFIA E ESTATISTICA. Censo Agropecuário 2006 - Agricultura Familiar: primeiros resultados - Brasil, Grandes Regiões e Unidades da Federação. Rio de Janeiro: IBGE, 2009.

Guanziroli, C. E.; Cardim, S. E. de C. S. (coord.). Novo Retrato da Agricultura Familiar: O Brasil Redescoberto. Brasília: Ministério do Desenvolvimento Agrário/Instituto Nacional de Colonização e Reforma Agrária, fev. 2000.

KEPNER, C. H.; TREGOE, B. B. O Administrador Racional: uma abordagem sistemática à solução de problemas e tomada de decisões. São Paulo: Atlas, 1976.

KUNZLER, E.C.; WIZNIEWSKY, C.R.F. A produção coletiva do espaço no Assentamento Conquista da Liberdade como base para o desenvolvimento sustentável. Campo-Território: Revista de Geografia Agrária, v.7, n.13, p.267-290, fev.,2012.

LEITE, S. P.; ÁVILA, R. V. Reforma agrária e desenvolvimento na América Latina: rompendo com o reducionismo das abordagens economicistas. Rev. Econ. Sociol. Rural, vol.45, no.3, Brasília, Jul./Set., 2007.

LIMA, A.P. de.; BASSO, N.; NEUMANN, P.S.; SANTOS, A.C. dos.; MULLER, A.G. Administração da Unidade de produção familiar. modalidades de trabalho com agricultores. 3. ed. Ijuí: Editora UNIJUí, 2005.

MACHADO, J.A.D. Análisis del sistema información-decisión en agricultores de regadio del Velle Medio del Guadalquivir. Tese (Doutorado em Economia Agroalimentar) - Universidade de Córdoba, Córdoba, Espanha. 1999. 
MARTINS, A. F.G. Potencialidades transformadoras dos movimentos camponeses no Brasil contemporâneo: as comunidades de resistência e superação do MST. São Paulo, 2004. Dissertação (Mestrado). Pós-Graduação em Ciências Sociais - PUCSP.

MINTZBERG, H. The manager's job: folklore and fact. Harvard Business Review. v. 53, n० 4, pp. 49-61, 1975.

MINTZBERG, H.; RAISINGHANI, D.; THÉORÊT, A. The Structure of "Unstructured" decision processes. Ithaca/New York, Administrative Science Quarterly, v.21, n.2, p.246-275, jun., 1976.

NAVARRO, Z. Desenvolvimento rural no Brasil: os limites do passado e os caminhos do futuro. Estudos Avançados, 15 (43), 2001.

ORTEGA, A. C. Políticas públicas territoriais rurais no Brasil. In: ORTEGA, A.C. e MOYANO-ESTRADA, E. (org.) Desenvolvimento em territórios rurais: estudos comparados de Brasil e Espanha. Campinas, Ed. Alínea, 2015.

PAYÉS, M. A. M.; SILVEIRA, M. A. A racionalidade econômica do empresário familiar. Jaguariúna, EMBRAPA-CNPMA (Documentos, 10),p.21p. 1997.

PLOEG, Jan Douwe van der. Sistemas de conocimiento, metáfora y campo de interacción: el caso del cultivo de la patata em el altiplano peruano. Agricultura y Sociedad, n056 p.143-166, 2000

PLOEG, J. D. Camponeses e impérios alimentares: lutas por autonomia e sustentabilidade na era da globalização. 1. ed. Porto Alegre: UFRGS, 2008.

REICHERT, L.J; GOMES M.C. O processo administrativo e a tomada de decisão de agricultores familiares em transição agroecológica. Revista de la Facultad de Agronomia La Plata, Argentina. v.112, n.2, p. 105-113, jul-dez, 2013.

SACCO ANJOS, F.; CALDAS, N. V. O futuro ameaçado: o mundo rural face aos desafios da masculinização, do envelhecimento e da desagrarização. Ensaios FEE, Porto Alegre, v. 26, n. 1, p. 661-694, jun. 2005.

SCHNEIDER, S. A pluriatividade na agricultura familiar. Porto Alegre: UFRGS, 2003b.

SCOPINHO, R. A. Sobre cooperação e cooperativas em assentamentos rurais. III Conferencia Internacional La obra de Carlos Marx y los desafíos del Siglo XXI. Anais..., 2006. Disponível em:

<https://www.nodo50.org/cubasigloXXI/congreso06/conf3_scopinho.pdf>

SEPULCRI, O. Gestão de Risco na Agricultura. 2a Prêmio Extensão Rural. EMATER. Paraná. 2006. Disponível em:

<http://www.emater.pr.gov.br/arquivos/File/Comunicacao/Premio_Extensao_Ru 
ral/2_Premio_2006/18_Gestao_Risco_Agric.pdf > . Acesso em: 12 de outubro 2012.

SILVA, P. M.; GOMES, M. C. ; CORRÊA, L. A. V. Racionalidade e inovação tecnológica: O agricultor familiar diversificado face ao processo de decisão da escolha da cultivar de milho. Rev. Fac. Agron. La Plata, Vol 112 (1): 35-43, 2013.

SMELTZER, L. R.; FANN, G. L.; NIKOLAISEN, V. N. Environmental Scanning Practices in Small Business. Journal of Small Business Management, Vol. 26(3), Jul. 1988.

SOLANO, C.; LEÓN, H.; PÉREZ, E.; HERRERO, M. The role of personal information sources on the decision-making process of Costa Rican dairy farmers. Agricultural Systems. v. 76: (1), p. 3-18, 2003.

SIMON, H. A. Administrative behavior: a study of decision making processes in administrative organizations. 4.ed. New York, The Free Press, 1997. (Edição especial comemorativa do $50^{\circ}$ aniversário da edição de 1947 com comentários de H.Simon).

SUTHERLAND, A.J., MCGREGOR, M.J., DENT, J.B., WILLOCK, J., DEARY, I., GIBSON, G., GRIEVE, R., MORGAN, O. Edinburgh farmer decision making study: Elements important to the farmer. In: BEERS, G.,HUIRNE, R.B.M., PRUIS, H.C. (Eds.), Farmers in Small-scale and Large-scale Farming in a New Perspective. Objectives, Decision Making and Information Requirements. Agricultural Economics. Research Institute. The Netherlands, p. 162-171. 1996.

TEIXEIRA, A.L., LIMA, J.B. O cotidiano administrativo de pequenos produtores de hortigranjeiros. In: Encontro anual da ANPAD. Salvador. Anais... Salvador: Associação Nacional dos Cursos de Pós-Graduação em Administração, v.5. 1993.

WANDERLEY, Maria de Nazareth Baudel. O campesinato brasileiro: uma história de resistência. Rev. Econ. Sociol. Rural, vol.52, supl.1, Brasília, 2014.

WEBER, Max. Economy and society. an outline of interpretive sociology. Berkeley: University of California, 1978.

XAVIER, José Humberto Valadares. Avaliação de sistemas de cultivo de milho grão sequeiro no contexto da agricultura familiar: uma aplicação da metodologia multicritério de apoio à decisão (MCDA). 2010. 318f. Tese (Programa de Pós Graduação em Sistemas de Produção Agrícola Familiar) - Universidade Federal de Pelotas, Pelotas, 2010. 


\section{Sobre os autores}

Ísis Mota Krüger, Mestre.

Mestre em Economia Aplicada - Universidade Federal de Pelotas - UFPel

Endereço para correspondência Rua General Câmara, 694 - CEP 96.600-000, Canguçu/RS

E-mail: isismk@gmail.com

\section{Mário Conill Gomes}

Doutor em Engenharia de Produção. Professor Associado - Depto. de Ciências Sociais Agrárias Faculdade de Agronomia Eliseu Maciel - UFPel - Universidade Federal de Pelotas

Endereço para correspondência: UFPel - Campus Capão do Leão - Campus Universitário, s/n. 96.010-900 - Capão do Leão - RS - Brasil.

E-mail: mconill@gmail.com 